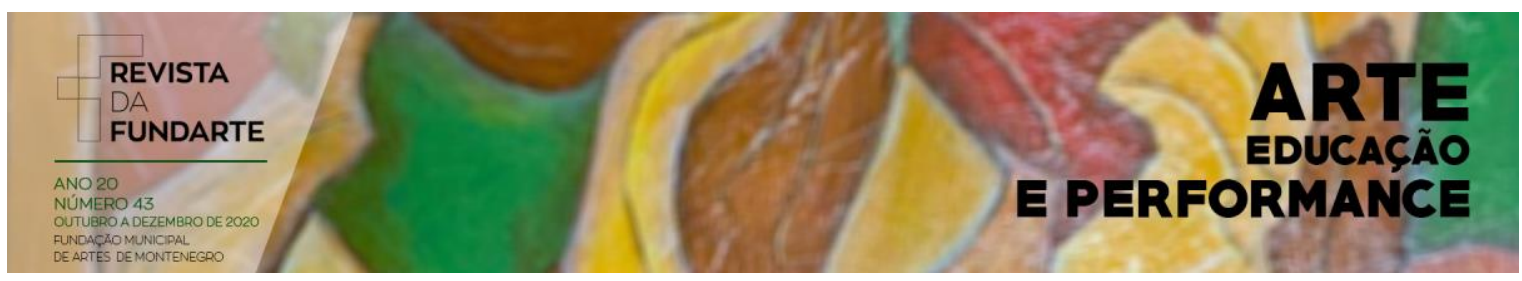

\title{
O ENSINO DE TEATRO, SEUS ESPAÇOS POSSÍVEIS E IMAGINÁRIOS
}

\author{
Rita Réus
}

Ernani Mügge

Daniel Conte

DOI: http://dx.doi.org/10.19179/2F2319-0868/2F734

RÉUS, Rita; MÜGGE, Ernani; CONTE, Daniel. O ensino de teatro, seus espaços possíveis e imaginários. Revista da FUNDARTE. Montenegro, p.01-16, ano 20, nำ43, outubro/dezembro de 2020. Disponível em: http://.seer.fundarte.rs.gov.br/index.php/revistadafundarte/index> 20 de dezembro de 2020. 


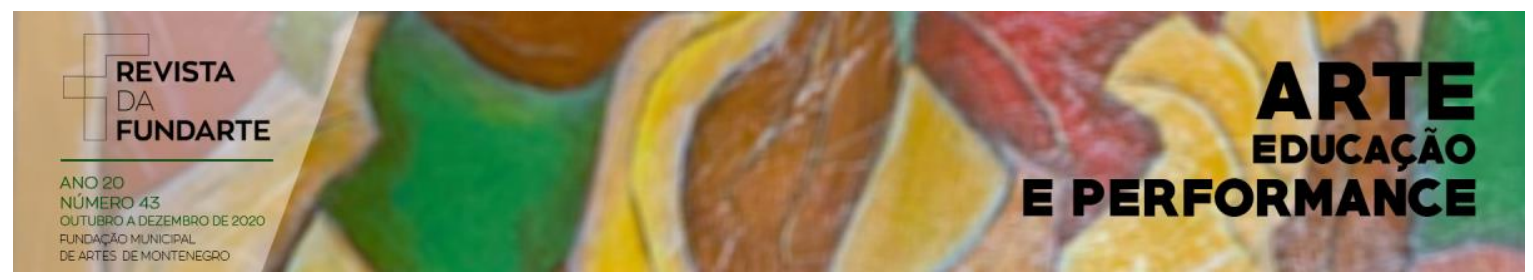

\title{
O ENSINO DE TEATRO, SEUS ESPAÇOS POSSÍVEIS E IMAGINÁRIOS
}

\author{
Rita Réus ${ }^{1}$ \\ Ernani Mügge ${ }^{2}$ \\ Daniel Conte 3
}

\begin{abstract}
Resumo: O presente artigo conjetura sobre o ensino de teatro no contexto escolar, promovendo a análise de práticas e explorando suas conexões com 0 imaginário, em uma perspectiva bachelardiana. Neste intuito, propõe uma reflexão quanto às estratégias desenvolvidas durante os processos de aprendizagem, correlacionando-os com conceitos estruturantes na relação com o outro e o espaço cênico. A proposta apresentada sublinha a importância de atividades de leitura e de arranjamento cênico no ambiente escolar. A construção de uma performance a partir de Morte e Vida Severina, de João Cabral de Melo Neto - um texto literário - ilustra um exercício estético da linguagem, consubstancializado em uma instrumentalização para o discente, a fim de favorecer seu reconhecimento do espaço social e, por consequência, do trânsito em sua territorialidade.
\end{abstract}

Palavras-chave: Ensino de Teatro; Imaginário; Espaço Cênico.

\section{THEATER TEACHING, ITS POSSIBLE SPACES AND IMAGINARIES}

\begin{abstract}
This article speculates on teaching theater in the school context, promoting the analysis of practices and exploring its connections with the imaginary, in a Bachelardian perspective. In this sense, it proposes a reflection on the strategies developed during the learning processes, correlating them with structuring concepts related to the other and the scenic space. The proposal presented stresses the importance of reading and scenic arrangement in the school environment. Building a performance from Morte e Vida Severina, by João Cabral de Melo Neto - a literary text -, it was possible to show an aesthetic exercise of language, embodied in an instrumentalization for the student, in order to favor its recognition of social space and, consequently, of the transit in its territoriality.
\end{abstract}

Keywords: Theater Teaching; Imaginary; Scenic Space.

\section{Considerações iniciais do objeto}

Este artigo propõe uma reflexão sobre o ensino do teatro e sobre o espaço que ele ocupa no processo de ensino e de aprendizagem. Para tanto, serão

\footnotetext{
1 Mestranda em Processos e Manifestações Culturais, Universidade Feevale; Especialista em Pedagogia da Arte, UFRGS/2009; Graduada em Teatro: Licenciatura, UERGS/2005; Professora de Teatro na Escola SESI de Ensino Médio Montenegro.

2 Doutor em Letras (UFRGS), com pós-doutorado em Cultura e Literatura (PNPD/CAPES). Pesquisador e professor permanente do Programa de Pós-graduação em Processos e Manifestações Culturais e do Mestrado Profissional em Letras (Universidade Feevale).

${ }^{3}$ Doutor em Literatura brasileira, portuguesa e luso-africana pela UFRGS. Professor e pesquisador do PPG de Processos e Manifestações Culturais e dos Mestrados Profissionais em Letras e Indústria Criativa da Universidade Feevale. Bolsista de Produtividade em Pesquisa CNPq.
}

RÉUS, Rita; MÜGGE, Ernani; CONTE, Daniel. O ensino de teatro, seus espaços possíveis e imaginários. Revista da FUNDARTE. Montenegro, p.01-16, ano 20, oㅡ 43, outubro/dezembro de 2020. Disponível em: http://.seer.fundarte.rs.gov.br/index.php/revistadafundarte/index $>20$ de dezembro de 2020. 


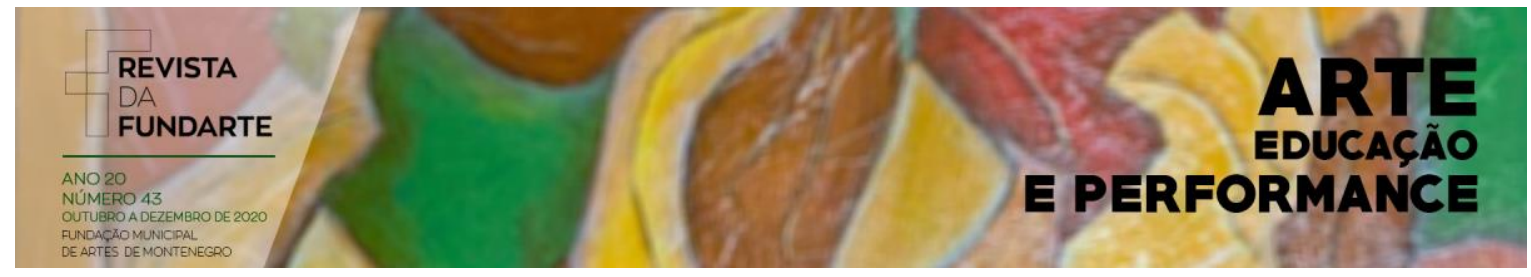

abordadas práticas teatrais desenvolvidas no espaço escolar e apresentadas possibilidades de criação de lugares possíveis e imaginários. A proposta parte da ideia de que a experienciação do fazer teatral pode ter como espaço físico um lugar constituído por paredes, teto e chão, formatado na grade curricular, um lugar que conforma o sujeito temporalmente. Já o espaço imaginário, caracteriza-se como um locus de infinitas possibilidades, criado no próprio espaço cênico. Este consiste numa proposta de construção de um onde, no qual os participantes exercitam sua imaginação por meio de jogos teatrais, dramáticos, técnicas de improvisação e de criação de cenas.

Para o desenvolvimento desta reflexão, servem de base estudos de Gaston Bachelard que trazem à tona o funcionamento do fenômeno humano como produtor do efeito de sentido que o sujeito empreende ao largo de sua vivência. Interessa, também, na análise, estudiosos como Jean Pierre Ryngaert e Viola Spolin, fundamentais para pensar a casa e o corpo de imagens suscitado por ela. Além disso, os referidos autores comportam reflexões sobre práticas possíveis de serem empregadas nas atividades cênicas e para evidenciar o modo como as conexões gestadas durante a experiência podem dar suporte ao processo de ensino e de aprendizagem, de modo que 0 aluno se sinta parte dele e possa alcançar o redimensionamento de microespacialidades, idiossincrasias performáticas que fazem do sujeito-ator o sujeito-sentido. Ademais, tem-se como horizonte o protagonismo do discente na ocupação desse lugar possível, uma vez que, segundo Bachelard, "todo espaço realmente habitado traz a essência da noção de casa" (1993, p. 25).

Nessa ordem, é perfeitamente possível afirmar que o imaginário desperta, na criação cênica e no exercício teatral, estratégias de imaginação que trabalham em uma perspectiva fundante desse sujeito, no espaço de criação. Consoante Bachelard,

RÉUS, Rita; MÜGGE, Ernani; CONTE, Daniel. O ensino de teatro, seus espaços possíveis e imaginários. Revista da FUNDARTE. Montenegro, p.01-16, ano 20, ํㅡ 43, outubro/dezembro de 2020. Disponível em: http://.seer.fundarte.rs.gov.br/index.php/revistadafundarte/index> 20 de dezembro de 2020. 


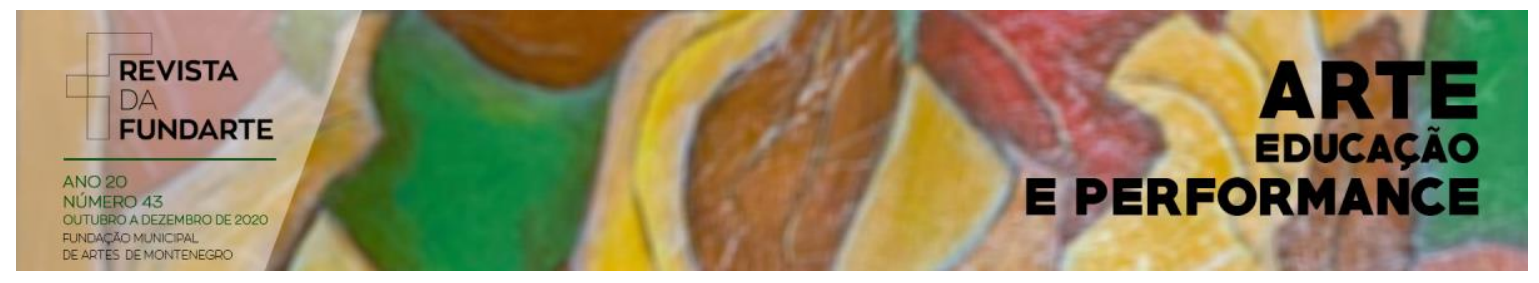

[...] veremos a imaginação construir "paredes" com sombras impalpáveis, reconfortar-se com ilusões de proteção, ou inversamente tremer atrás de grossos muros, duvidar das mais sólidas muralhas. Em suma na mais interminável das dialéticas, o ser abrigado sensibiliza os limites do seu abrigo. Vive a casa em sua realidade e em sua virtualidade, através do pensamento e dos sonhos. (BACHELARD, 1993, p. 25).

Considerando que o desenvolvimento dos alunos está relacionado a uma aprendizagem que vai além de uma prática docente voltada à memorização de conceitos abstratos e, na maioria das vezes, descontextualizados, torna-se substancial que sejam empregadas diversas formas e abordagens que permitam, aos discentes, relacionarem-se com o objeto de estudo, o qual constitui-se de performances subjetivacionais. Faz-se necessário que a compreensão do material seja potencializada por meio de atividades que suscitem a construção de imagens bem como seu processo de elaboração, sejam elas de que categoria forem, como, por exemplo, releituras, exposições, filmes, diálogos, objetos ou construção de cenas.

O trabalho de execução da prática pedagógica que contempla o ensino de teatro, tem como um de seus objetivos o desenvolvimento da criatividade artística, com vistas ao desenvolvimento humano e à geração de processos mais amplos de percepção do locus de trânsito e de seu espaço enunciativo. Portanto, os jogos teatrais são um meio para expandir as potencialidades criativas dos alunos. Viola Spolin observa que, ao jogar,

Todas as partes do indivíduo funcionam juntas como uma unidade de trabalho, como um pequeno todo orgânico dentro de um todo orgânico maior que é a estrutura do jogo. Dessa experiência integrada, surge o indivíduo total dentro do ambiente total, e aparece o apoio e a confiança que permite ao indivíduo abrir-se e desenvolver qualquer habilidade necessária para a comunicação dentro do jogo. (SPOLIN, 1987, p. 6).

O jogo, nestes termos, consolida-se como um elo entre o espaço possível e o espaço imaginado, proporcionando, ao aluno - jogador - um universo de faz-deconta, uma textura imaginária permeada pelas instâncias do real e do onírico. Esse movimento imagético, constituinte da trama, cria mundos possíveis, nos quais a ação é a metáfora para devaneios. Bachelard é categórico ao afirmar que, ao devaneio, pertencem

RÉUS, Rita; MÜGGE, Ernani; CONTE, Daniel. O ensino de teatro, seus espaços possíveis e imaginários. Revista da FUNDARTE. Montenegro, p.01-16, ano 20, ㄲo 43, outubro/dezembro de 2020. Disponível em: http://.seer.fundarte.rs.gov.br/index.php/revistadafundarte/index> 20 de dezembro de 2020. 


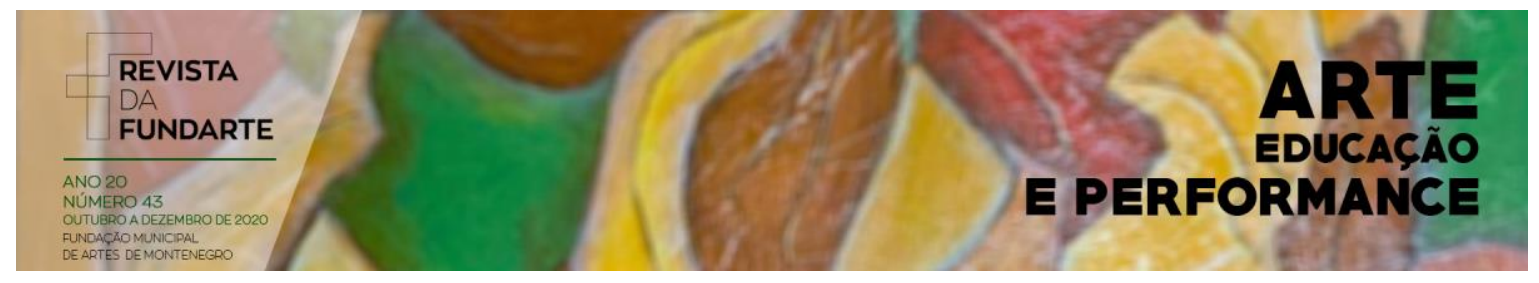

[...] valores que marcam o homem em sua profundidade. $O$ devaneio tem mesmo um privilégio de autovalorização. Ele usufrui diretamente de seu ser. Então, os lugares onde se viveu o devaneio reconstituem-se por si mesmos num novo devaneio. É exatamente porque as lembranças das antigas moradas são revividas como devaneios que as moradas do passado são imperecíveis dentro de nós.( BACHELARD, 1993, p. 26).

A morada, portanto, é claramente a representação do corpo-ser. Este, ao instituir-se como parte de uma prática cênica, disponibiliza seu corpo e todas as memórias da bacia semântica do imaginário - imagens, memórias e projeções para desenvolver possibilidades outras de estar no mundo.

A arte, de modo geral, contribui no processo de tomada de consciência, tornando as formas de ver o mundo mais abertas e os indivíduos mais sensíveis à realidade cotidiana, uma vez que estabiliza suas narrativas desde uma subjetivação verticalizada do imaginário. Ao encenar a rede simbólica da realidade, o sujeitosentido caminha em direção à compreensão da malha significativa de sua condição política. Ainda, favorece a criação de um potente imaginário local, apoiado nas raízes e na criatividade coletiva do presente. Além disso, a arte (re)orienta as poéticas locais que dão sentido à vida em comunidade, por meio da criação de novas possibilidades de existência, de formas de relação com o outro e com o meio, como exercício do lúdico, da imaginação e dos (re)cantos semânticos. As artes da cena são ferramentas importantes de descoberta e formação da identidade cultural de um indivíduo, mas, também, a de um grupo. Por meio delas, o sujeito acessa a possibilidade de expressar o que pensa e como percebe a realidade em que vive. Todo ser carrega em si a potencialidade criativa, basta que encontre um espaço propício que o ajude a liberar sua criatividade cênica e capacidade dramática. Esse espaço ergue-se como um lugar possível e imaginado, onde o ator possa se sentir seguro para narrar-se como ser pleno de sentido, pois

$\mathrm{Na}$ vida do homem, a casa afasta contingências, multiplica seus conselhos de continuidade. Sem ela o homem seria um ser disperso. Ela mantém o homem através das tempestades do céu e das tempestades da vida. É o corpo e a alma. É o primeiro mundo do ser humano. Antes de ser "jogado no mundo" como professam as metafísicas apressadas, o homem é colocado no berço da casa. E sempre, nos nossos devaneios, ela é um grande berço. (BACHELARD, 1993, p. 26).

RÉUS, Rita; MÜGGE, Ernani; CONTE, Daniel. O ensino de teatro, seus espaços possíveis e imaginários. Revista da FUNDARTE. Montenegro, p.01-16, ano 20, ํㅡ 43, outubro/dezembro de 2020. Disponível em: http://.seer.fundarte.rs.gov.br/index.php/revistadafundarte/index $>20$ de dezembro de 2020. 


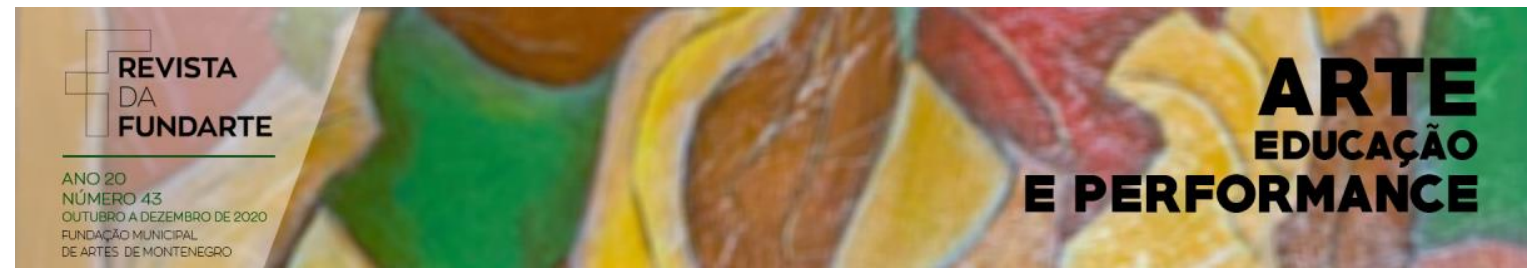

O conforto e a estabilidade, gerados em um espaço possível do fazer teatral, abre portas de lugares imaginários e imaginados, de maneira a favorecer a emergência de imagens mais profundas e repletas de significado para a linguagem, para a comunicação e a expressão, pretendidas no ato criativo. Por essa razão, fazse mister que, ao pensar as atividades, o professor programe as condições necessárias para a construção de espaços que propiciem o desenvolvimento das percepções imaginárias, as quais levam o sujeito a entender-se como narrativa única, singular e subjetivada da arte.

\section{Construindo espaços: uma prática viável}

Nas aulas de teatro, a metodologia empregada está intimamente ligada às subjetividades que vão constituir universos outros pretendidos no processo criativo. Nessa ordem, é importante, em um primeiro momento, que os alunos conheçam as práticas teatrais e os elementos básicos do fazer dramático, para conformarem uma base organizada de condução dos participantes, a fim de que as atividades se conectem, servindo de lastro uma para a outra. Contudo, em um mesmo encontro, podem existir diferentes momentos: o momento 1, que é o instante de aquecimento, constitui-se de exercícios de respiração, corpo e voz, relação com espaço e o outro; o momento 2, o da expressão corporal, consta de pesquisa do repertório de movimentos com exercícios de expressão corporal e vocal, jogos teatrais e dramáticos, em dupla e em grupo, seleção/ criação de textos e/ou imagens; já o momento 3, é o espaço-tempo da composição de cenas; e, por último, o momento 4, que aponta para o compartilhamento, o que significa o encerramento do encontro, um espaço em que cada participante fala sobre sua percepção de como está sendo o processo e de como se percebe dentro dele.

Esses quatro momentos revelam o percurso de uma única aula, constituída de exercícios que pretendem proporcionar uma série de estruturas necessárias ao fazer teatral e que se abrem para a construção de um pré-texto ${ }^{4}$. A aula pode ser um

\footnotetext{
4 "O pré-texto é a forma como a atividade ou o tema é introduzido ao grupo, a fim de envolvê-lo emocional e intelectualmente com o processo. O pré-texto vai ativar e dinamizar o contexto e as situações do Drama, sugerindo papéis e atitudes aos participantes, além de apresentar os

RÉUS, Rita; MÜGGE, Ernani; CONTE, Daniel. O ensino de teatro, seus espaços possíveis imaginários. Revista da FUNDARTE. Montenegro, p.01-16, ano 20, ํㅡ 43, outubro/dezembro de 2020. Disponível em: http://.seer.fundarte.rs.gov.br/index.php/revistadafundarte/index> 20 de dezembro de 2020.
} 


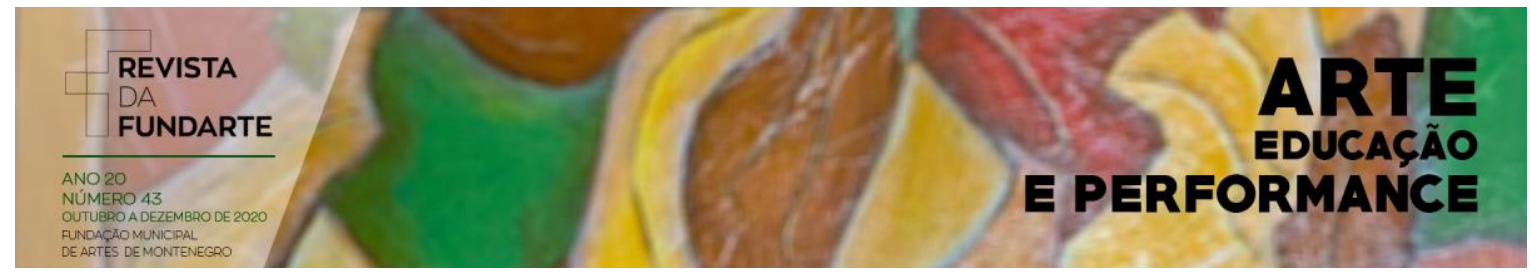

fim em si mesma ou ter sequência, somando-se a outros percursos que formarão etapas de desenvolvimento do processo de criação.

\section{Pré-textualização dramática: lugares imaginados a partir de Morte e vida Severina, de João Cabral de Melo Neto}

As histórias narradas no teatro, em sua maioria, são variações de histórias já contadas anteriormente. Apesar disso, quando uma história é contada, mesmo que ela seja amplamente conhecida, é importante que os envolvidos se apropriem dela e a tornem uma versão de seu constructo imaginário. Nesse viés, mais importante do que o que é contado é o como é contado. Ainda, quando se cria uma dramaturgia ou se faz uso de textos já prontos, elabora-se, também, uma série de imagens que se inter-relacionam e, por consequência, criam novos significados. Estes significados devem extrapolar a leitura pessoal, devendo abrir-se para possíveis leituras do espectador, criar elos com seu imaginário e com tessituras do universo onírico, "e não esqueçamos que são esses valores de sonho que se comunicam poeticamente de alma para alma." (BACHELARD, 1983, p. 36). Isso significa que os efeitos de sentidoS produzidos na relação emissão-recepção, passarão por uma complexidade, o que sígnica que conformará não só o lugar do processo enunciativo, como, também, a própria condição receptiva, de modo a permitir a elaboração de uma nova e única performance sobre o outrora contado.

Para exemplificar o procedimento, é apresentada, em seguida, uma prática desenvolvida em uma escola a partir da obra Morte e vida Severina, de João Cabral de Melo Neto.

Inicialmente foi proposta a leitura da obra aos alunos, informando que ela seria objeto para a realização de uma atividade cênica que contemplasse três componentes curriculares: teatro, literatura e música. Após a leitura, foram motivados a narrarem sua experiência com o texto, momento em que alguns relatos apontaram para dificuldades de compreensão de vocábulos ou, mesmo, da narrativa

antecedentes da ação e propor o engajamento do grupo nas tarefas e papéis necessários ao desenvolvimento da narrativa." (DESGRANGES, 2017, p. 127).

RÉUS, Rita; MÜGGE, Ernani; CONTE, Daniel. O ensino de teatro, seus espaços possíveis e imaginários. Revista da FUNDARTE. Montenegro, p.01-16, ano 20, ํㅡ 43, outubro/dezembro de 2020. Disponível em: http://.seer.fundarte.rs.gov.br/index.php/revistadafundarte/index $>20$ de dezembro de 2020. 


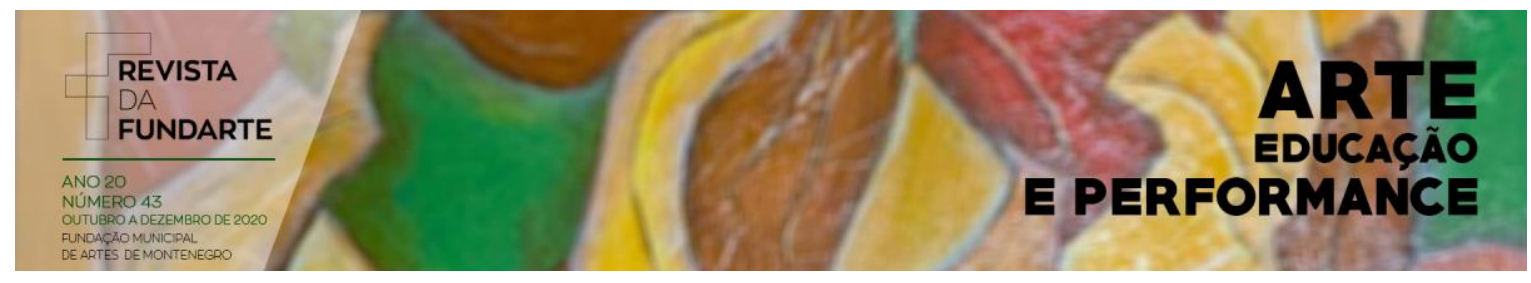

como um todo. Isso, todavia, não foi impedimento para a continuidade do trabalho. Enquanto mediadora da aprendizagem, coube à professora, o papel de fomentar espaços de interação dos alunos com a obra. Para isso, ambientou a sala de teatro por meio da utilização de recursos tecnológicos (projeções de imagens, microfones, músicas); além disso, um chapéu de palha e um grande tecido de malha preta (aproximadamente $3 \mathrm{~m} \times 1,4 \mathrm{~m}$ ) também foram providenciados. A atividade teve início com um jogo que proporcionou o estreitamento da conexão entre os alunos e a história. Dispostos em círculo, cada discente precisou retirar de uma pequena bolsa uma bolinha de papel, a qual colocou no centro do círculo, vocalizando um fazer próprio. A ideia propunha uma conexão com a imagem criada na história, quando Severino, em sua jornada, chega à casa de uma senhora e, durante a conversa, perguntado sobre o que fazia no lugar em que morava, dá respostas que não preenchem o perfil desejado para trabalhar com ela. Em resposta a essa enunciação de Severino, ela diz que necessita de alguém que saiba fazer ladainha, encomendar defunto ou, mesmo, rezar, pois vivia de ajudar a morte. Na versão em quadrinhos à qual os alunos tiveram acesso, aparece, nessa passagem, a imagem de uma mulher que semeia pequenas caveiras. Estas, no exercício, foram substituídas por bolas de papel, como é possível verificar nas imagens (Figura 1 e 2).

Figura 1 - Caveiras em papel I, 2018.

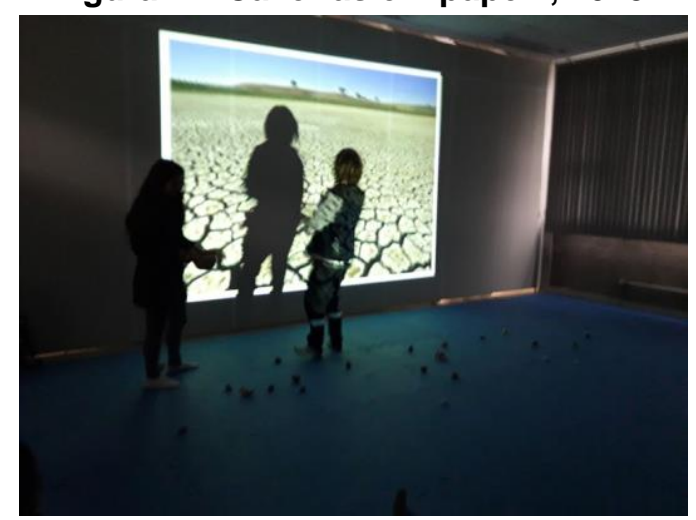

Fonte: acervo dos autores.

RÉUS, Rita; MÜGGE, Ernani; CONTE, Daniel. O ensino de teatro, seus espaços possíveis e imaginários. Revista da FUNDARTE. Montenegro, p.01-16, ano 20, ํㅡ 43, outubro/dezembro de 2020. Disponível em: http://.seer.fundarte.rs.gov.br/index.php/revistadafundarte/index> 20 de dezembro de 2020. 


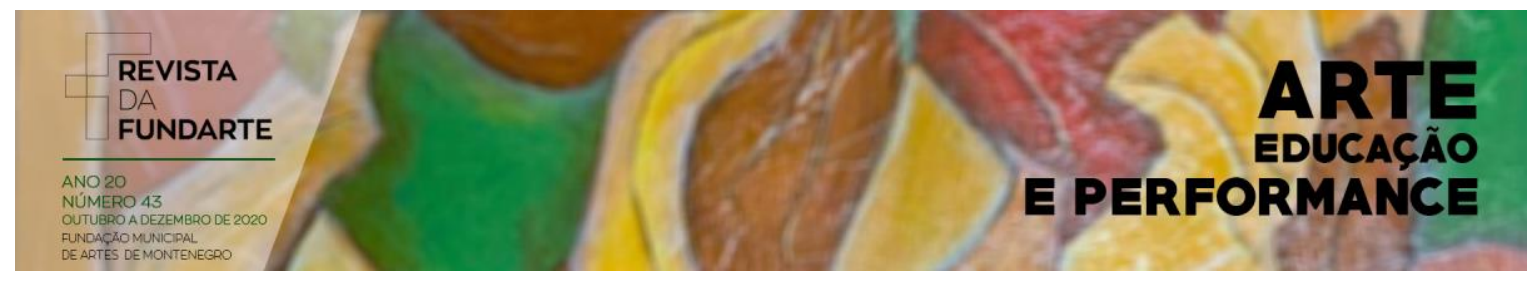

Figura 2 - Caveiras em papel II, 2018.

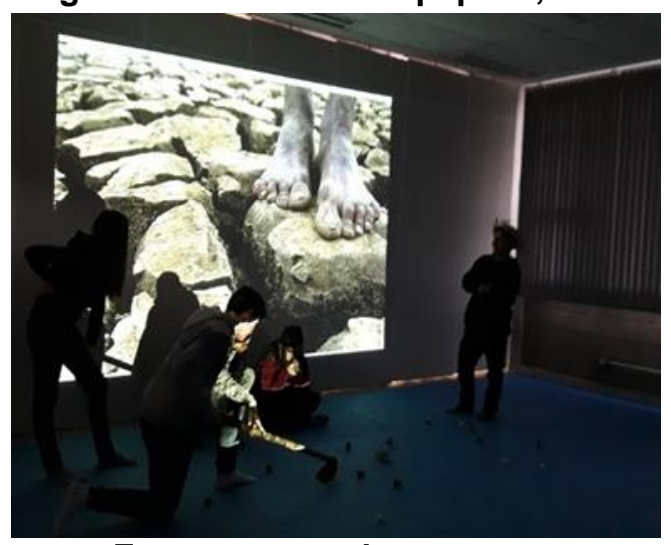

Fonte: acervo dos autores.

A atividade seguiu com rezas e rimas, entoadas pelos alunos. No movimento seguinte, improvisaram-se algumas outras cenas da materialidade ficcional, para as quais foram disponibilizados recursos sonoros e instrumentos musicais.

No espaço do contemporâneo, a concepção de dramaturgia, de texto e de cena foi expandida. Dessa forma, é possível pensar nas diferentes construções cênicas e em seus formatos como uma faceta das diversas narrativas hodiernas. É importante salientar que, quando a parede da sala de aula é, ao mesmo tempo, o solo do sertão, a leitura feita pelos alunos não mais se realiza apenas a partir do código escrito, mas também da imagem que se constrói dentro do fenômeno da linguagem dramática. Ao imbuir-se do ato enunciativo do drama, deslocando-se da condição de narratário para a de enunciador, remodelando o texto com suas palavras, exige-se mais do que a mera projeção de voz, exige-se, de modo simultâneo, que o ator assimile e relacione as informações contidas no texto, para poder jogar com os elementos de cena e com o outro, o colega. Não se pode, entretanto, na condição de professor, almejar que as improvisações e as criações sejam perfeitas ou estejam de acordo com o que se considera o ideal, uma vez que o redizer ficcional coloca a significação em uma espiral de sentido que condensa em si a condição singular de permanente construção.

A relação do aluno com o texto deve possibilitar diferentes modos de interpretar uma mesma ação ou situação, desde que se perceba a essência do que ela traz. O processo de releitura é um processo de abertura para o desvelar das

RÉUS, Rita; MÜGGE, Ernani; CONTE, Daniel O ensino de teatro, seus espaços possíveis e imaginários. Revista da FUNDARTE. Montenegro, p.01-16, ano 20, ํㅡ 43, outubro/dezembro de 2020. Disponível em: http://.seer.fundarte.rs.gov.br/index.php/revistadafundarte/index> 20 de dezembro de 2020. 


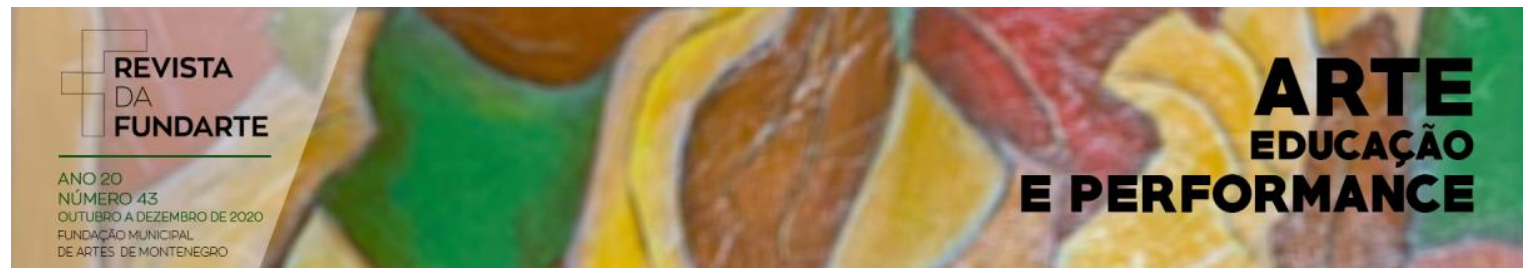

imagens construídas também pelos alunos, isso em função das diversas possibilidades de interpretação do texto, que não só acionam a imaginação dos leitores, mas recuperam a funcionalidade de sua bacia imaginária. Bachelard afirma que a fenomenologia "prefere colocar o ser em movimento a aquietá-lo. Ela convida o ser a viver fora dos abrigos do inconsciente, a entrar nas aventuras da vida, a sair de si. E, naturalmente, sua ação é salutar." (1993, p. 30).

A releitura cria, nesses termos, movimento; o texto propõe que os leitores saiam de si e arquitetem, em um espaço diverso, uma nova projeção, constituída, agora, de um eu-outro. Além disso, a releitura de uma obra jamais é incoerente, já que decorre da compreensão que o sujeito constrói ao largo de sua leitura.

$\mathrm{Na}$ atividade apresentada aos alunos, o exercício de recriar, proposto pela professora, tornou ação aquilo que estava no papel. Funcionou, também, como um convite para que o aluno visitasse as imagens elaboradas por ele, em seu processo imaginativo, durante a leitura. Nessa ordem, é possível crer que toda leitura revela, em alguma medida, as impressões e os registros do inconsciente de cada leitor. Para além, a forma e a estrutura como ele desenha suas ações e composições cênicas trazem à tona aquilo que habita seus espaços imaginários.

A experiência teatral possibilita, todavia, tanto um percurso fragmentado, conforme descrito no exercício supracitado, quanto um caminho com estruturas mais precisas, como será possível verificar na exposição que segue.

\section{Caminhos da montagem cênica}

Uma montagem cênica, quando propõe a composição de uma sequência que tenha como objetivo traçar rumos que conduzam a etapas que complexifiquem o processo de desenvolvimento de criação, ou seja, criar um movimento inicial (elaboração de um pré-texto), projetando-o como produto, há que considerar as vontades de criação, os resultados dos experimentos e os anseios do grupo. Assim, durante as primeiras etapas, com as quais se pretende articular 0 fazer experimental, os indivíduos são estimulados a mergulhar em si, a descobrirem-se como jogadores, atuadores, e, simultaneamente, a acender uma luz sobre aquilo imaginários. Revista da FUNDARTE. Montenegro, p.01-16, ano 20, ㄲo 43, outubro/dezembro de 2020. Disponível em: http://.seer.fundarte.rs.gov.br/index.php/revistadafundarte/index> 20 de dezembro de 2020. 


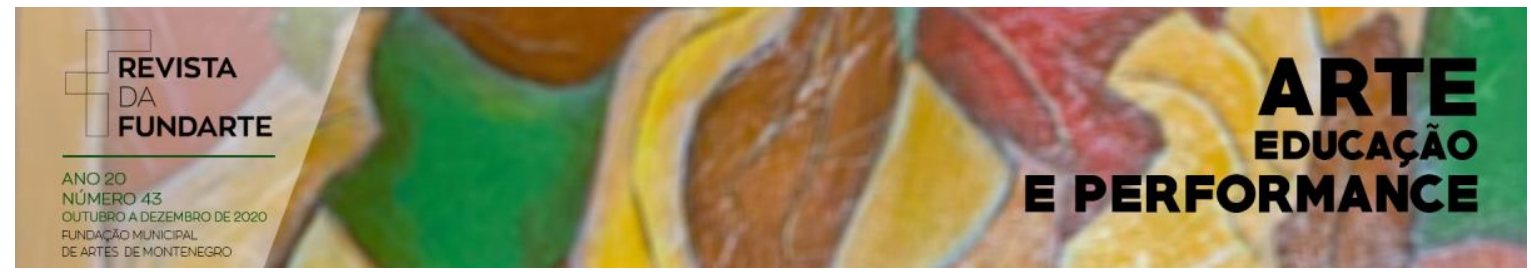

que, em seu cotidiano, não se costuma revelar. Essa luz, conforme observação do fenomenólogo francês, é "a lâmpada à janela e o olho da casa". Ele ainda aponta para a imagem da lâmpada, referindo-a ao "reino da imaginação, [que] jamais se acende do lado de fora" (BACHELARD, 1983, p. 51). E, se é dentro do espaço íntimo que essa luz acende, faz-se necessário o uso da reflexão crítica sobre o processo criativo, sobre sua relação com as ideias individuais e coletivas, para, só então, costurar a montagem cênica. O movimento busca um equilíbrio entre as imagens produzidas pelos indivíduos, entre o coletivo e o que se pretende compor com elas, no intento de priorizar a escuta do grupo, uma vez que, "em nossas casas grudadas umas às outras, temos menos medo. A tempestade em Paris não tem contra o sonhador a mesma capacidade ofensiva que contra a casa de um solitário" (BACHELARD, 1983, p. 45).

A proposição de elaborar uma montagem cênica suscita a possibilidade de conceber um lugar imaginário, um lugar que não é palpável, mas que pode passar a existir a partir de um movimento imagético estabilizado nos devaneios subjetivos dos atores. Essa existência se funda na relação, nas trocas entre os indivíduos, na composição com os elementos de cena e, em especial, no jogo. O jogar, nesse sentido, está vinculado às atividades lúdicas, aos jogos teatrais e dramáticos, às técnicas de percepção corporal e espacial, bem como às práticas teatrais que constituem os fundamentos básicos das artes cênicas. Nessa perspectiva, propõemse exercícios que estimulem a concentração, a presença e a percepção do espaço de si e do outro, uma vez que

\begin{abstract}
A verdadeira escuta exige estar totalmente receptivo ao outro, mesmo quando não se olha para ele. Essa qualidade não se aplica somente ao teatro, mas é essencial ao jogo, uma vez que assegura a veracidade da retomada e do encadeamento. A escuta do parceiro comanda, em larga medida, a escuta da plateia. Estar alerta é uma forma de sustentação do outro, qualquer que seja a estética da representação. (RYNGAERT, 2009, p. 56).
\end{abstract}

Essa etapa culmina na criação de um roteiro, que será utilizado como base, além de ser uma referência, para que os alunos construam esse lugar imaginário, compreendendo um processo de subjetivação que traz, não só a rede onstituinte de imaginários. Revista da FUNDARTE. Montenegro, p.01-16, ano 20, ㄲo 43, outubro/dezembro de 2020. Disponível em: http://.seer.fundarte.rs.gov.br/index.php/revistadafundarte/index> 20 de dezembro de 2020. 


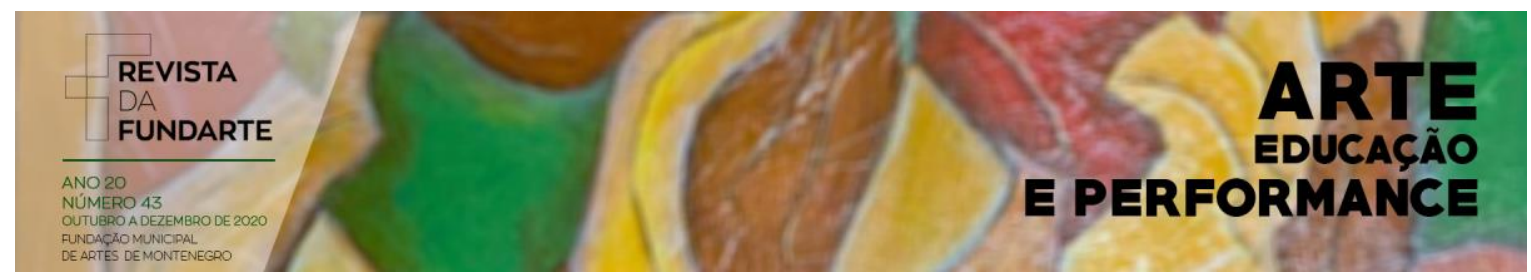

cada participante, mas também um entendimento do fazer coletivo e da possibilidade do devaneio dramático. Para Jean-Pierre Ryngaert,

$\mathrm{Na}$ tradição de improvisação com roteiro, os jogadores inventam, em linhas gerais, uma narrativa prévia tentam jogar. O roteiro dá segurança para aqueles que se sentem paralisados pela improvisação sem nenhum ponto de referência e faz parte das propostas mínimas de ponto de partida da improvisação. (RYNGAERT, 2009, p.115).

Na proposta em questão, todavia, lançou-se mão de algumas improvisações, com o objetivo de, por meio da criação do roteiro, gestar uma estrutura, não necessariamente fixa, mas que pudesse nortear o processo.

Figura 3 - Improvisação I, 2018.

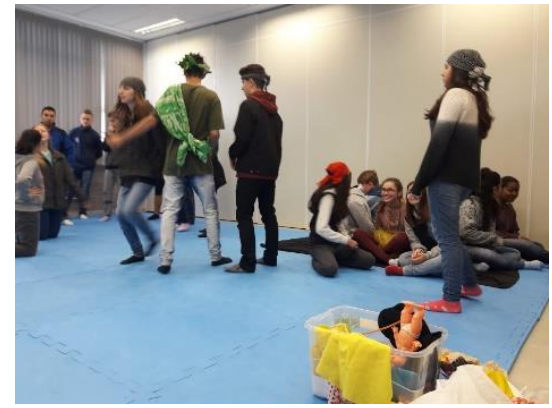

Fonte: acervo dos autores.

Figura 4 - Improvisação II, 2018.

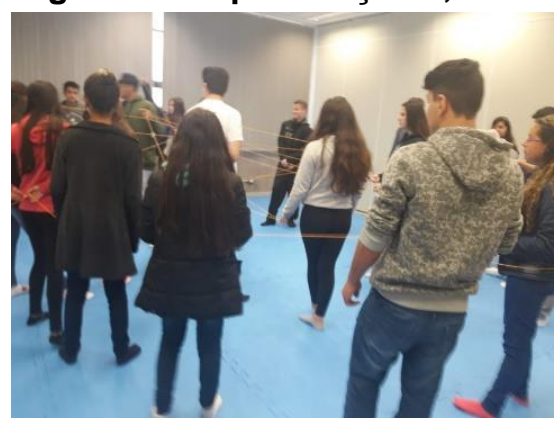

Fonte: acervo dos autores.

A metodologia da dramatização da poética ficcional teve seguimento com a elaboração de um roteiro junto aos alunos. Os roteiros originaram as montagens cênicas: por meio dos exercícios e do compartilhamento de ideias, foram escolhidas as cenas que se acreditava serem fundantes da narrativa. Cada espaço imaginário imaginários. Revista da FUNDARTE. Montenegro, p.01-16, ano 20, ㄲo 43, outubro/dezembro de 2020. Disponível em: http://.seer.fundarte.rs.gov.br/index.php/revistadafundarte/index> 20 de dezembro de 2020. 


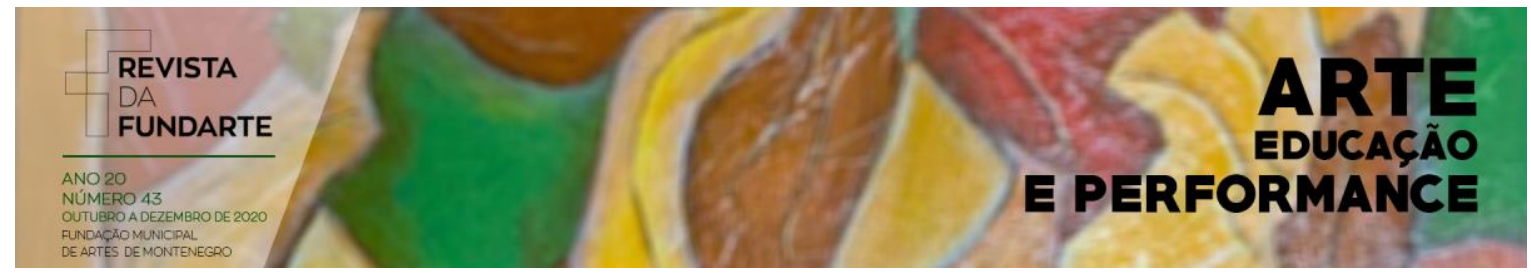

se constituiu no fazer; não havia, portanto, uma estrutura a ser copiada. O trabalho criativo produziu imagens que se entrelaçaram para construir senhas montagens.

Figura 5 - Montagem Cênica I, 2018.

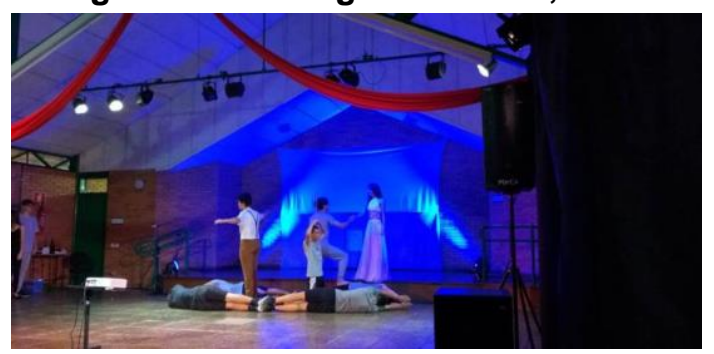

Fonte: acervo dos autores.

Figura 6 - Montagem Cênica II, 2018.

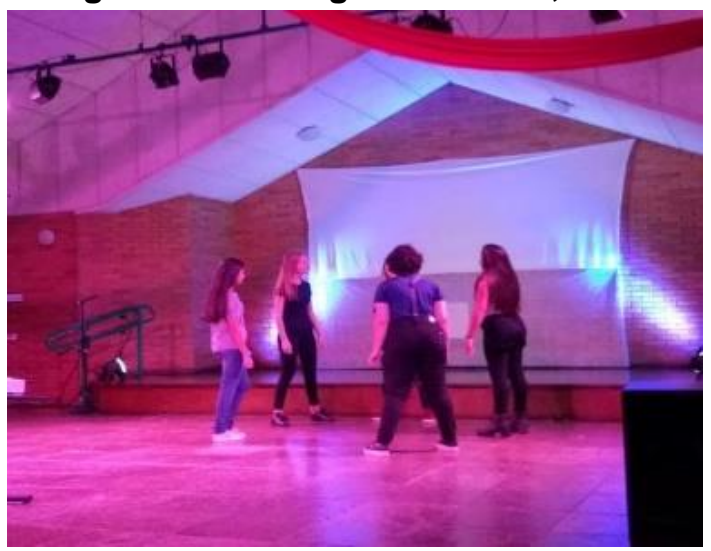

Fonte: acervo dos autores.

As composições se relacionaram com os espaços possíveis, os quais, entretanto, ofereceram limitação aos alunos, tanto no que diz respeito ao tema, quanto no que concerne à linguagem teatral. Assim, buscaram transcender as fronteiras por meio de espaços imaginários. A criação destas montagens, todavia, foi apenas um recorte da praxis desenvolvida nas aulas de teatro; é, também, uma obra resultante de um processo que vale por si mesmo, de um estudo, que passa pelos corpos e mentes dos participantes, e que corrompe narrativas habitualmente estruturadas, e cria novos espaços de interação e possibilidades outras de ver uma história. Ao fazê-lo, cria outro nível de complexidade e intimidade, fundado no desejo pela criação, pois "não há intimidade verdadeira que repila. Todos os espaços de intimidade designam-se por uma atração" (BACHELARD, 1983, p. 31). imaginários. Revista da FUNDARTE. Montenegro, p.01-16, ano 20, oㅡ 43, outubro/dezembro de 2020. Disponível em: http://.seer.fundarte.rs.gov.br/index.php/revistadafundarte/index> 20 de dezembro de 2020. 


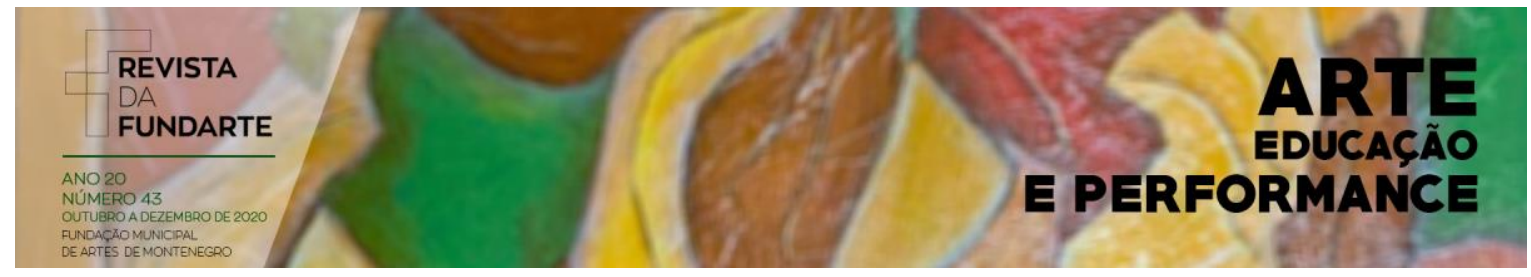

Algumas cenas foram construídas e, depois de uma breve discussão, reestruturadas e cerzidas umas às outras, compondo a montagem. Nessa etapa, almejou-se valorizar o fazer coletivo e, ao mesmo tempo, respeitar o valor da individualidade na construção da linguagem dramática. Importante ressaltar que o espaço possível do drama conforma condições operacionais que edificam imagens, proporcionando aos diferentes perfis de alunos, oportunidade de ampliar sua vivência teatral. Em um panorama mais amplo, é possível pensar que esse locus imaginarius é um lugar de aproximação entre a linguagem teatral, diferentes textos, manifestações artísticas e o indivíduo.

As montagens cênicas concebidas e dramatizadas junto aos alunos compuseram, entre outras atividades, a Mostra Cultural da escola, a qual foi idealizada com a intenção de socializar, com a comunidade, os processos de ensino e de aprendizagem construídos no âmbito escolar. Para o processo de criação vivenciado pelos alunos durante o ano letivo, fez-se importante sair do espaço protegido da sala de aula e levar a público os mundos possíveis que ali passaram a existir. Nessa ordem, constatou-se a potencialidade transformadora que o teatro pode desencadear na vida e na forma de ver e de pensar das pessoas. Ademais, percebeu-se a emergente necessidade de estimular a criação cênica e incentivar a formação de novos olhares, novas subjetivações, que vão desnaturalizar narrativas culturais e criar possibilidades para que o ator social encontre na arte perspectivas de experienciação, de estar no mundo e que seja também a casa, na perspectiva bachelardiana.

\section{À guisa de conclusão}

Este texto trouxe à luz, a partir da materialidade dramática, a concepção de espaços possíveis na ordem da bacia semântica do imaginário, estabelecendo uma relação dialógica entre o pensamento de Bachelard e práticas de ensino do teatro. Para tanto, teve como foco um recorte específico de experiências, ocorridas no ano de 2018, em um espaço formal de educação, as quais tiveram como propósito principal redimensionar os espaços das salas de aula, para que os alunos tivessem imaginários. Revista da FUNDARTE. Montenegro, p.01-16, ano 20, ㄲo 43, outubro/dezembro de 2020. Disponível em: http://.seer.fundarte.rs.gov.br/index.php/revistadafundarte/index> 20 de dezembro de 2020. 


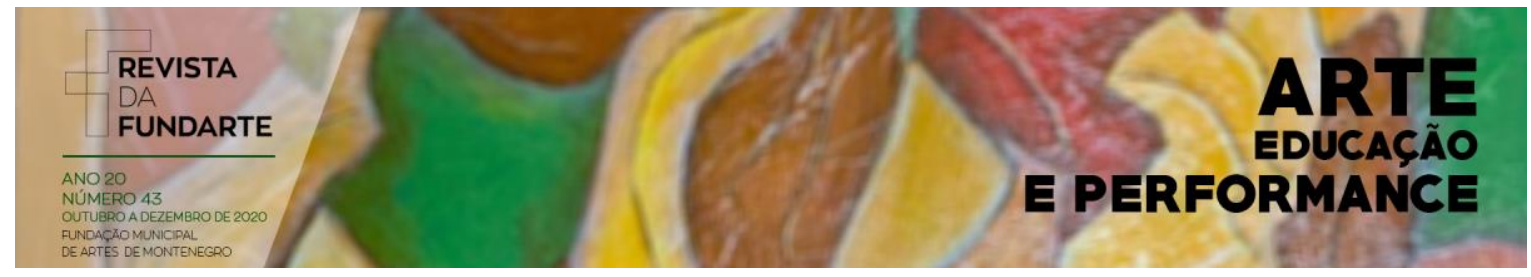

condições de descentralizarem-se da ordem comum, para conceber espaços possíveis. Na ordem do senso comum, o teatro pode até ser visto como um universo palpável, contudo acredita-se que a experiência dramática poderá desencadear a criação de espaços imaginários, se conseguir em sua condução, tornar o espaço possível, algo próximo da ideia de casa. Ademais, aqueles que estiverem no processo do fazer teatral, conseguirão lidar melhor com seus medos, anseios, vaidades, com imagens e vozes silenciadas. Ao conseguir transportarem-se à cena e dar corpo ao interior dos cômodos, eles sentirão

\begin{abstract}
claramente que esse calafrio já não é um medo humano, é um medo cósmico, um medo antropocósmico que faz eco à grande lenda do homem entregue a situações primitivas. Do porão talhado na rocha ao subterrâneo, do subterrâneo a água parada, passamos do mundo construído para o mundo sonhado; passamos do romance para a poesia. Mas o real e o sonho são agora uma unidade. (BACHELARD, 1993, p. 41).
\end{abstract}

A junção do real e do sonho é, também, a funcionalidade palpável que compõe a fantasia e a beleza da arte teatral, onde os espaços imaginários são mundos possíveis, onde a performatização do efeito de sentido causado pela literatura favorece a rearticulação da rede simbólica do imaginário e conduz o sujeito-sentido à compreensão do mundo a partir do exercício da linguagem dramática. Ressalta-se, da mesma forma, a importância de movimentos que redizem a poética ficcional oferecendo a ela uma nova roupagem, que permite seu redimensionamento de significação na ordem social. Por fim, a proposta apresentada, neste estudo, evidencia a relevância de práticas de leitura e de construção cênica no ambiente escolar, que favorecem não só o exercício estético da linguagem, mas também instrumentalizam o discente a reconhecer-se no espaço social e, por consequência, a transitar em sua territorialidade identitária. imaginários. Revista da FUNDARTE. Montenegro, p.01-16, ano 20, ㄲo 43, outubro/dezembro de 2020. Disponível em: http://.seer.fundarte.rs.gov.br/index.php/revistadafundarte/index> 20 de dezembro de 2020. 


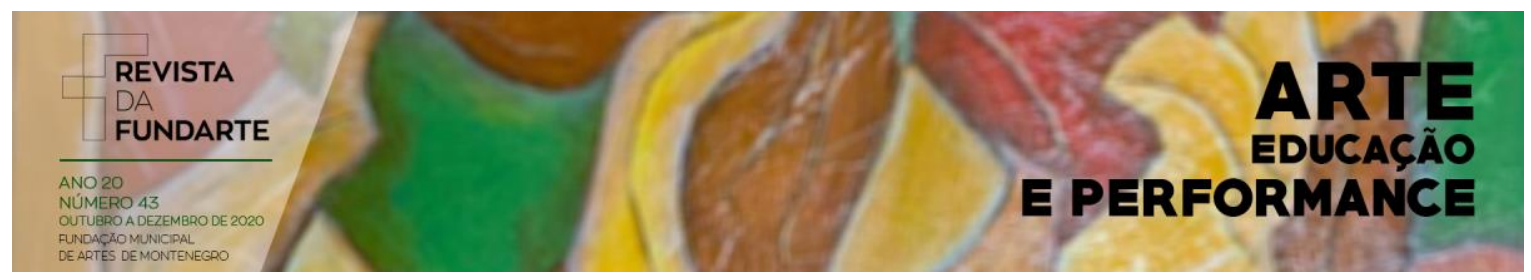

\section{Referências:}

BACHELARD, Gaston. A casa. Do porão ao sótão. O sentido da cabana. In: $A$ poética do espaço. São Paulo: Martins Fontes, 1993.

DESGRANGES, Flávio. Pedagogia do Teatro: Provocação e dialogismo. São Paulo: Hucitec, 2017.

RYNGAERT, Jean-Pierre. Jogar, representar. São Paulo: Cosac \& Naify, 2009.

SPOLIN, Viola. Improvisação para o teatro. São Paulo: Perspectiva, 1987. 